\title{
"International women day" de Angela Eiko Okumura: tradução comentada de uma poesia política e feminista
}

\section{Angela Eiko Okumura's poetry "international women day": commented translation of a political and feminist poetry}

\section{“Día internacional de la mujer" por Angela Eiko Okumura: traducción comentada de una poesía política y feminista}

(iD) Neiva de Aquino Albres

Universidade Federal de Santa Catarina (UFSC), Florianópolis, Santa Catarina, Brasil E-mail: neiva.albres@ufsc.br

iD) Larissa Fernandes Dias

Universidade Federal de Santa Catarina (UFSC), Florianópolis, Santa Catarina, Brasil E-mail: diaslarissa67@gmail.com

Resumo: Neste estudo são abordadas as principais estratégias adotadas na tradução da poesia em Língua Brasileira de Sinais "INTERNATIONAL WOMEN DAY", da poetisa surda Angela Eiko Okumura, para a Língua Portuguesa escrita. Com base nos Estudos da Tradução e Interpretação de Línguas de Sinais - ETILS e estudos da literatura surda, desenvolvemos algumas reflexões sobre os desafios encontrados e as escolhas de tradução realizadas. Utilizamos a metodologia de tradução comentada. Apresentamos os problemas tradutórios encontrados, assim como a perspectiva dos tradutores sobre as escolhas feitas. A fim de descrever o processo de construção de sentido e tornar a poesia esteticamente

1 Esta pesquisa foi desenvolvida durante a disciplina de “Literatura Surda I" do curso de Letras-Libras da UFSC, ministrada pela professora Dra. Neiva de Aquino Albres, que teve como objetivo incentivar os alunos à prática de tradução e à investigação científica. 
interessante para o público alvo, na tradução final, buscou-se preservar as características do gênero poesia.

Palavras-chave: Tradução comentada. Poesia. Literatura em Sinais. Libras.

Abstract: This work presents the main strategies used in translating the poem "INTERNATIONAL WOMEN DAY", by the deaf poetess Angela Eiko Okumura, from Brazilian Sign Language into written Portuguese. Based on Sign Language Translation and Interpreting Studies - SLTIS and studies from deaf literature, we have carried out some reflections concerning the main problems encountered when translating and the translation choices. We have used the annotated translation methodology. We present the translation problems encountered as well as the translator's perspective on the performed choices. In order to describe the process of meaning construction and make the poem esthetically interesting for the target-public, in the final translation it was sought to preserve the characteristics presented in the genre of poetry.

Keywords: Annotated translation. Poetry. Signed Literature. Libras.

Resumen: Este estudio aborda las principales estrategias adoptadas por la poeta sorda Angela Eiko Okumura, en lengua portuguesa de señas brasileña "DÍA INTERNACIONAL DE LA MUJER", en portugués escrito. Basado en estudios de traducción e interpretación de lenguajes de señas - ETILS y estudios de literatura sorda, desarrollamos algunas reflexiones sobre los desafíos encontrados y las elecciones de traducción realizadas. Utilizamos la metodología de traducción comentada. Presentamos los problemas de traducción encontrados, así como la perspectiva de los traductores sobre las elecciones realizadas. Para describir el proceso de construcción del significado y hacer que la poesía sea estéticamente interesante para el público objetivo, en la traducción final buscamos preservar las características de la poesía de género.

Palavras Clave: Traducción anotada. Poesía. Literatura firmada. Libras

Submetido em 13 de abril de 2020.

Aceito em 09 de dezembro de 2020.

Publicado em 08 de julho de 2021. 
"International women day" de Angela Eiko Okumura: tradução comentada de uma poesia... Neiva de Aquino Albres • Larissa Fernandes Dias

\section{Introdução}

A especificidade da enunciação de texto poético em uma língua de sinais tem sido estudada recentemente no campo da literatura, linguística e tradução. A produção artística poética é vivida e sentida por meio da visão, pela alma em expressão corporificada e envolvida de sentimentos do autor da obra de forma singular. A produção estética provém de movimentos e expressões, registrada em vídeo e, por vezes, editada e lapidada.

A tradução de uma poesia de Libras para português escrito possui complexidade tradutória singular, pois exige competência tradutória e estética, emprego de termos específicos da língua que requer um conhecimento aprofundado de língua, cultura e literatura para que a obra seja entregue ao público que se destina provocando sentidos similares na tradução.

Este trabalho aborda uma tradução comentada para o português do poema "International Women Day" em Língua de Brasileira de Sinais, Libras, de autoria da artista surda Angela Okumura, disponível na plataforma Instagram no perfil "4sentidosmedia". Delineamos como finalidade uma proposta de tradução da poesia com a análise do processo tradutório, contribuindo também com o campo da pesquisa em Estudos da Tradução e Interpretação de Línguas de Sinais - ETILS, enfatizando na tradução de poesia.

Nessa conjuntura, este trabalho tem seus objetivos desdobrados em três aspectos: empreender a análise de tradução produzida em ambiente acadêmico (curso de formação de tradutores Libras-Português); problematizar a reflexão do processo de tradução obtido por meio das análises desenvolvidas a partir dos comentários dos tradutores; servir de insumo para outros tradutores, como para estudiosos do campo dos Estudos da Tradução e para docentes de tradução, na medida em que ajuda a entender o processo de construção de sentidos de texto. 
"International women day" de Angela Eiko Okumura: tradução comentada de uma poesia... Neiva de Aquino Albres • Larissa Fernandes Dias

\title{
Poesia como expressão da literatura surda
}

Os estudos que inspiram este trabalho provêm do conjunto de textos produzidos por Bakhtin e o círculo, a que se convencionou considerar a língua como a experiência de comunicação, pensamento e constituição singular que vive o ser humano em interações situadas e entre sujeitos, além de um conjunto de autores que estudam línguas de sinais, literatura surda e os temas recorrentes dessas produções.

\begin{abstract}
A literatura surda está relacionada com a cultura surda. A literatura da cultura surda, contada em língua de sinais de determinada comunidade linguística, é constituída pelas histórias produzidas em língua de sinais pelas pessoas surdas, pelas histórias de vida que são frequentemente relatadas, pelos contos, pelas lendas, fábulas, piadas, poemas sinalizados, anedotas, jogos de linguagem e muito mais. (KARNOPP; MACHADO, 2006, p. 3).
\end{abstract}

A comunidade surda tem se apropriado cada vez mais das tecnologias digitais que possibilitam videogravar a expressão linguística tanto para a comunicação cotidiana quanto para comunicação científica ou expressão artística. Essas tecnologias, atualmente, estão ao alcance de nossas mãos e assim criam, expõem e podem fazer circular obras em uma velocidade impressionante. A comunidade surda (por estar inserida em um mundo globalizado) toma para si os mais diversos temas, e em suas produções é possível visualizar as múltiplas vozes que ecoam na expressão artístico literária, o que até recentemente não era tão perceptível, visto que tinha-se a ideia de que a literatura surda seria apenas um tipo de literatura oral.

A literatura surda tem uma tradição diferente, próxima a culturas que transmitem suas histórias oral e presencialmente. Ela se manifesta nas histórias contadas em sinais, mas o registro de histórias contadas no passado permanece na memória de 
"International women day" de Angela Eiko Okumura: tradução comentada de uma poesia... Neiva de Aquino Albres • Larissa Fernandes Dias

algumas pessoas ou foram esquecidas. Assim, estamos privilegiando a literatura surda contemporânea, após o surgimento da tecnologia, da gravação de histórias através de fitas VHS, CD, DVD ou de textos impressos que apresentam imagens, fotos e/ ou traduções para o português. O registro da literatura surda começou a ser possível principalmente a partir do reconhecimento da Libras e do desenvolvimento tecnológico, que possibilitaram formas visuais de registro dos sinais. (KARNOPP, 2008, p. 2).

Complementamos que com as atualizações da internet e redes sociais, conforme momento atual, os autores passam a produzir e a elaborar efeitos estéticos nos vídeos por meio de edição e efeitos especiais. Dessa forma, as produções literárias não contam mais somente com a expressão linguística em Libras, mas também com um conjunto de edições, efeitos especiais que colaboram para a produção estética e para a construção de sentidos pelo leitor.

No passado, antes do advento de novas tecnologias de registro filmado e dos meios de comunicação da internet, como Youtube, Facebook, por exemplo, era nos encontros face-a-face das comunidades surdas que aconteciam os momentos de contação de histórias e outras performances artísticas em língua de sinais, que não eram registrados. Obviamente ficaram os registros na memória pessoal dos que tiveram a oportunidade de participar desses acontecimentos. (SUTTON-SPENCE et al., 2016, p. 86).

Nesta pesquisa, aborda-se os relatos tradutórios, escolhas, estratégias e discute-se os problemas de tradução enfrentados, baseando-se nos autores que bebem da perspectiva de análise dialógica do discurso - ADD (BRAIT, 2006; DE PAULA, 2013; ROHLING, 2014). A visão tradicional de tradução pauta-se na concepção de que traduzir é um ato puramente mecânico de reprodução linguístico-textual do texto-fonte em outra língua, como um produto 
"International women day" de Angela Eiko Okumura: tradução comentada de uma poesia... Neiva de Aquino Albres • Larissa Fernandes Dias

cópia do original (BASSNETT, 2003; PYM, 2016). Contudo, os estudos pós-estruturalistas e pós-modernos dispersam seu olhar para aspectos culturais, sociais e econômicos para além dos aspectos estritamente linguísticos que envolvam a tradução.

O problema de originalidade é maior ainda quando se discute o texto poético. O conflito entre assemelhar-se ao texto de partida e o compromisso de criar efeitos de sentido e ao gênero literário que detém algumas especificidades é recorrente entre estudiosos da tradução.
A atividade do tradutor pode ser pensada com um ato marcado pelo dilema de evitar tanto impor o modo de ser de uma data cultura, repetindo palavras e metáforas que vêm de outra cul- tura, como impor ao texto traduzido o modo de ser de sua pró- pria cultura, matando o estilo e as ênfases do conjunto. Logo, manter esse difícil equilíbrio é necessariamente um ato ético. (SOBRAL, 2003, p. 203).

Consideramos a tradução nesse entremeio. Assim, "a tradução leva as marcas do sujeito tradutor tal como qualquer poema leva, carrega e exibe as marcas do poema que o gerou" (LARANJEIRA, 1993, p. 124). A tradução já não é o mesmo que o texto de partida e tão pouco algo produzido sem motivação nele. Autores indicam a impossibilidade de se manter a homogeneidade de conteúdo e forma do texto original, mas não questionam a possibilidade de se traduzir, contanto que se considere o tradutor um artista.

O "problema da tradução criativa", como aponta Campos (1992, p. 46), está na não aceitação do "labor de tradução competente como tal e válido como arte" (CAMPOS, 1992, p. 47). Da mesma maneira, Paes (1990, p. 32) concorda que, em se tratando de tradução de poesias, o tradutor trabalha além do signo, trabalha com "correlação de valores", confrontando os constituintes da linguagem e produzindo compensações. Dessa forma, para se "traduzir poesia há de se criar - re-criar - sob pena de esterilização 
"International women day" de Angela Eiko Okumura: tradução comentada de uma poesia... Neiva de Aquino Albres • Larissa Fernandes Dias

e petrificação, o que é pior do que a alternativa de "trair"'" (CAMPOS, 1976, p. 19).

\section{Metodologia de pesquisa}

Desenvolvemos um estudo fundamentado em abordagem qualitativa, compreendido como estudo de caso usando um corpus de tradução, mais precisamente uma tradução comentada. Configura-se como uma pesquisa descritiva voltada ao processo. Desenvolveu-se a tradução pelo sentido preservando as características do gênero discursivo.

O texto traduzido foi de uma poesia em Libras de autoria de Angela Eiko Okumura e disponível na página "4sentidosmidia" e publicada no site Instagram. Os procedimentos e instrumentos de pesquisa utilizados foram a execução da tradução, analisando trechos em "unidades de sentido" do vídeo em Libras, construindo uma versão em língua portuguesa escrita (tradução), o que pode ser cotejada com as estrofes da poesia.

No processo de realização da tradução comentada registrou-se em um "diário de tradução" os problemas enfrentados, as possíveis soluções, as justificativas das escolhas tradutórias e os comentários sobre os trechos traduzidos. O vídeo é apresentado no formato poesia em Libras, logo, foi necessário estudar o gênero poesia, assistindo (ler) outros vídeos de poesias para compreender como é sinalizado esse gênero textual. Após compreender como é estruturada uma poesia em Libras se iniciou o estudo de poesias no português sobre direitos e conquistas das mulheres.

Portanto, para realizar a tradução foi assistido o vídeo e, conforme a compreensão, iniciou-se uma estrutura correspondente à poesia do português com estrofes, rimas e sentido apreendidos da expressão em Libras. Iniciou-se, primeiramente, pelo estudo do texto de partida (vídeo), assistindo diversas vezes para identificar o conteúdo e as mensagens que a autora do texto queria apresentar 
"International women day" de Angela Eiko Okumura: tradução comentada de uma poesia... Neiva de Aquino Albres • Larissa Fernandes Dias

ao seu público falante de Libras, estudo do contexto político e histórico como também da métrica poética usada pela autora.

Como procedimento de pesquisa também se adotou o registro dos documentos pesquisados e textos paralelos estudados (documentação). Para a apresentação da análise optamos por dispor os textos paralelos em tabelas por estrofes, o texto de partida em Libras e o texto de chegada em português escrito. Logo, a Libras não será apresentada em formato de transcrição com uso de glosas, ${ }^{2}$ pois cada falante compreende e utiliza uma sinalização própria. Dessa maneira, serão apontados os segundos em que cada estrofe foi estruturada, para que o leitor assista o vídeo e acompanhe em português. O vídeo está disponível na conta "4sentidosmidia" do Instagram. ${ }^{3}$

\section{Análise da poesia traduzida: uma tradução comentada}

Seguindo a metodologia de estudo de "tradução comentada", apresentamos as características do texto, a autora, o contexto político e social, as tradutoras e os comentários da tradução.

\section{Sobre a poesia e suas configurações genéricas}

Esse texto é um exemplar de produção de gênero poético cuja principal marca vem a ser as associações harmoniosas de sinais, gestos, ritmos e expressão corporal em Libras, algo que comove e sensibiliza o leitor.

\footnotetext{
2 Para McCleary, Viotti e Leite (2010), em uma transcrição de Libras para português escrito a glosa tem a função de nomear o sinal e a sua forma, sendo necessário garantir um vínculo unívoco entre a palavra usada para a glosa. Ressaltam ainda que, para a apresentação e análise de trechos de discurso espontâneo ou semiespontâneo, o sistema de glosas simples é bastante limitado. Quando há dados linguísticos compostos por sequência gestual e pantomímica, os pesquisadores podem optar por registrá-la utilizando um texto descritivo/narrativo.

3 https://www.instagram.com/p/BuvY17NIDdC/?igshid=1qfolcydwte44
} 
"International women day" de Angela Eiko Okumura: tradução comentada de uma poesia... Neiva de Aquino Albres • Larissa Fernandes Dias

\section{Quadro1: Dados do texto de partida}

\begin{tabular}{|c|c|}
\hline Título do texto de partida & "INTERNATIONAL WOMEN DAY" \\
\hline Autora do texto de partida & Angela Eiko Okumura \\
\hline $\begin{array}{l}\text { Lugar de produção do texto de } \\
\text { partida }\end{array}$ & Florianópolis, Santa Catarina, Brasil. \\
\hline $\begin{array}{l}\text { Lugar de recepção do texto de } \\
\text { partida }\end{array}$ & $\begin{array}{l}\text { Brasil } \\
\text { No Instagram, 1,380 visualizações } \\
\text { No Facebook, } 47.000 \text { visualizações e } 1000 \text { compartilhamentos } \\
\text { No Youtube, } 466 \text { visualizações }\end{array}$ \\
\hline $\begin{array}{l}\text { Dimensão temporal da publica- } \\
\text { ção do texto de partida }\end{array}$ & Março de 2019 em ocasião do dia internacional das mulheres \\
\hline $\begin{array}{l}\text { Característica do local em que } \\
\text { o texto base foi publicado }\end{array}$ & $\begin{array}{l}\text { Diante dos novos contextos de publicação e consumo de } \\
\text { literatura surda e devido à popularização das tecnologias di- } \\
\text { gitais, o formato de obras digitais, multimodais, ou seja, com } \\
\text { linguagens híbridas, tem se multiplicado. Essa produtora fez } \\
\text { uso de plataformas midiáticas como Instagram, Facebook e } \\
\text { Youtube para divulgar a poesia. Essas plataformas permitem } \\
\text { compartilhamentos em redes sociais pessoais ou pela dispo- } \\
\text { nibilização do link por outros meios eletrônicos como e-mail, } \\
\text { whatsapp, entre outros. }\end{array}$ \\
\hline $\begin{array}{l}\text { Motivação da autora para a } \\
\text { escritura do texto de partida }\end{array}$ & $\begin{array}{l}\text { A autora queria compartilhar a história de luta das mulheres, } \\
\text { homenageá-las e sensibilizar a sociedade para o reconheci- } \\
\text { mento do poder feminino. }\end{array}$ \\
\hline
\end{tabular}

Fonte: Elaborado pelas autoras (2020).

\section{Explorando os momentos da poesia}

A poesia se inicia com a incorporação de mulheres trabalhando em uma fábrica, remetendo ao fato histórico da fábrica têxtil de Nova York em 1911 que pega fogo ocasionando a morte de 125 mulheres. Os anos passam e as mulheres continuam trabalhando como escravas, fatos históricos são vividos, como guerras, e as mulheres continuam a "bater seus cartões". Unidas em movimento social, acreditaram na possibilidade de igualdade de condições. 
"International women day" de Angela Eiko Okumura: tradução comentada de uma poesia... Neiva de Aquino Albres • Larissa Fernandes Dias

Até que em 8 de março de 1975 são reconhecidas por meio de um dia especial para as mulheres. Em 2019 a marcha continua pelos seus direitos. Essa é uma poesia feminista, pois apesar de descrever lamentáveis fatos históricos, a autora acredita na igualdade social, política e econômica entre os sexos.

\section{Apresentando a autora da poesia}

A autora da poesia Angela Eiko Okumura é surda, formada em Letras-Libras pela Universidade Federal de Santa Catarina (2018). Em seu período de formação nessa universidade teve oportunidade de participar de muitas atividades de extensão que contribuíram com o desenvolvimento de sua atuação como artista, autora de poesias, tradutora e atriz. Participou do elenco da série bilíngue (primeira de ficção bilíngue, na Língua Brasileira de Sinais (Libras) e em português) chamada Crisálida e protagoniza a personagem Morgana. ${ }^{4}$

Figura 1: Foto de perfil da autora Angela Eiko

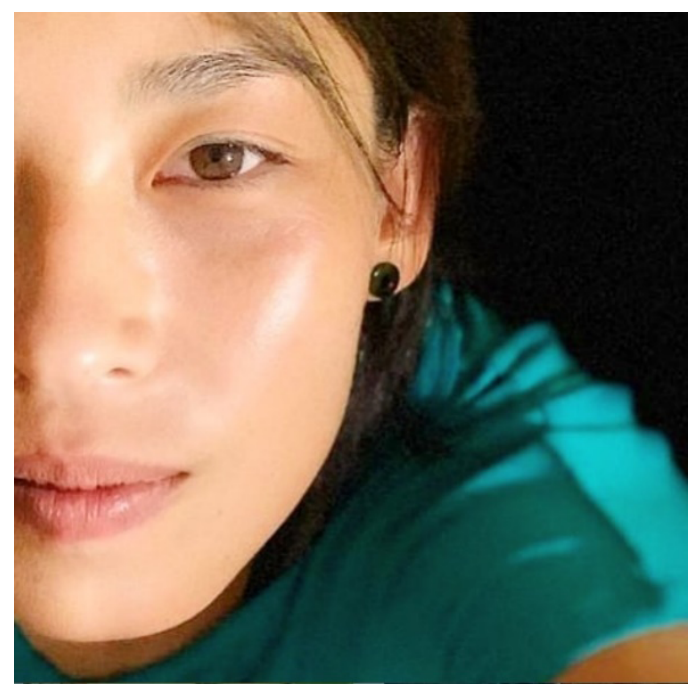

Fonte: Conta "angeiko" na rede social Instagram.

4 Crisálida, uma produção de Florianópolis, foi criada por Alessandra da Rosa Pinho e dirigida por Serginho Melo. A série é uma parceria entre a Arapy Produções, Raça Livre Produções e TVi Televisão e Cinema. 
"International women day" de Angela Eiko Okumura: tradução comentada de uma poesia... Neiva de Aquino Albres • Larissa Fernandes Dias

Angela Eiko participou de cursos de Literatura Surda, seminários, congressos, saraus de poesias em Libras, festivais nacionais ("Festival do Folclore Surdo", "Os craques da Libras") realizados na Universidade Federal de Santa Catarina (UFSC), como também do "3 ${ }^{a}$ arte e Libras em ciclo" pela Universidade Estadual de Santa Catarina (UDESC). A autora foi constituindo-se como uma pessoa surda que cria e recria um produto estético a partir de suas vivências e dos temas que circulam na comunidade surda. ${ }^{5} \mathrm{~A}$ poetisa surda trabalha na empresa "4 Sentidos" que desenvolve atividades de tradução, interpretação, produção em Libras e consultoria.

\section{Momento político da construção da poesia (obra)}

A poesia foi produzida para veiculação em 8 de março de 2019, dia em que se comemorava o dia das mulheres, pela empresa "4 Sentidos". Nos anos anteriores a 2019 observou-se maior acesso a informações às mulheres surdas, por meio de traduções como da lei maria da penha para a Libras (CAS-MS, 2016), ${ }^{6}$ e Lei Maria da Penha comentada com a campanha "Diga não à violência contra a muIher, denuncie!", 7 da tradução para Libras da cartilha "Violência Doméstica - Perguntas e Respostas" (SANTOS; STUMPF, 2019), como também por encontros regionais e encontro nacional de mulheres surdas, promovendo maior consciência sobre diversos tipos de violência sofridos pelas mulheres (PERLIN; VILHALVA, 2016).

\section{Sobre as tradutoras}

A obra foi traduzida na disciplina de Literatura Surda 1 do curso de Letras-Libras da Universidade Federal de Santa Catarina por Larissa Fernandes Dias e por Neiva de Aquino Albres em processo

\footnotetext{
5 O currículo lattes de Angela Eiko é: http://lattes.cnpq.br/4281505098241164.

6 Cf. https://www.youtube.com/watch?v=j0jlQhHtfxs\&t=466s.

7 Cf. https://www.youtube.com/watch?v=m5fGIf8DRjE

$8 \mathrm{Cf}$. https://www.youtube.com/watch?v=-pm46Vh0byM\&t=18s
} 
"International women day" de Angela Eiko Okumura: tradução comentada de uma poesia... Neiva de Aquino Albres • Larissa Fernandes Dias

de estudo e tradução comentada. A tradução foi produzida durante o segundo semestre de 2019. As autoras do artigo são tradutoras Libras-Português e pesquisadoras. Larissa Fernandes desenvolve iniciação científica no curso de Letras-Libras da UFSC e Neiva Albres é pesquisadora vinculada ao Programa de Pós-graduação em Estudos da Tradução (PGET) da UFSC.

\section{O processo}

Para a construção da tradução desenvolveu-se o trabalho de pesquisa da história e de produções com o mesmo gênero discursivo, como também a consulta a exemplos de traduções com tema similar. A tradução foi produzida em meio ao desenvolvimento de uma disciplina curricular do curso Letras-Libras da UFSC, de "Literatura surda", dessa forma, outras estratégias foram usadas, como o estudo de materiais para leitura indicados no curso, discussões em grupo, e diálogos de dúvidas específicas com colegas tradutores e com a professora da disciplina.

Durante a realização da tradução ficaram evidentes as diversas dificuldades que permearam a pesquisa. Primeiramente, o fato de uma das autoras ser uma tradutora aprendiz e ter que lidar com todos os conhecimentos, dificuldades e estratégias de uma tradução que exige esforço e dedicação. Também, a insegurança ao realizar algumas escolhas tradutórias, acreditando que poderiam ser representadas de outra maneira.

Contudo, ao longo deste estudo, foram apresentadas a justificativa de escolha do texto de partida, as reflexões teóricas conforme os autores discutem, o processo metodológico utilizado para realizar a tradução comentada, uma breve análise das expressões escolhidas e por fim os possíveis resultados e conclusões obtidas nesta pesquisa.

Para isso, foi necessário que as tradutoras começassem os primeiros passos da tradução realizando um mergulho na poesia e 
"International women day" de Angela Eiko Okumura: tradução comentada de uma poesia... Neiva de Aquino Albres • Larissa Fernandes Dias

sua história, como nos estudos das línguas. A partir da primeira proposta de tradução, as negociações de sentidos do texto foram sendo construídas entre as duas autoras, concomitante a estudos e reflexões. Em um projeto de tradução, o tradutor, a partir do texto do autor, cria um discurso, "organiza elementos para construir o discurso", considera as formas de composição comuns aos gêneros discursivos e as formas arquitetônicas (SOBRAL, 2008, p. 72).

\section{A tradução e seus comentários}

Apresentamos a seguir a tradução desenvolvida, seguida dos comentários sobre o processo de tradução. Em virtude do espaço delimitado para escrita deste artigo, não podemos abordar todas as questões interessantes de análise do processo tradutório dessa obra. Dessa forma, delimitamos para este artigo a questão da traduzibilidade de aspectos históricos, de edição do vídeo e métricos, como também os efeitos de modalidade. Dividimos a poesia em estrofes para apresentação e discussão.

\section{Quadro 2: Primeira Estrofe}

\begin{tabular}{|l|l|}
\hline POESIA EM LIBRAS & TRADUÇÃO PARA O PORTUGUÊS \\
\hline De 01 a 08 segundos do vídeo & Primeira Estrofe \\
\hline & Em épocas remotas, \\
& $\begin{array}{l}\text { Nossa felicidade era inexistente } \\
\text { Representadas como máquinas de produção } \\
\end{array}$ \\
\hline
\end{tabular}

Fonte: Elaborado pelas autoras (2020).

A autora mostra diversas personagens trabalhando com a imagem em preto e branco, o que remete a uma época antiga. Na tradução, o projeto discursivo identifica que as mulheres traba- 
"International women day" de Angela Eiko Okumura: tradução comentada de uma poesia... Neiva de Aquino Albres • Larissa Fernandes Dias

Ihavam demais em funções operárias e sentiam-se infelizes por estarem sujeitas àquela jornada de trabalho. Não se optou por expressar todas as tarefas manuais desenvolvidas pelas mulheres como apresentado pela pantomima na tradução, mas sim em expressar o sentimento de insatisfação e de trabalho excessivo ocorrido na época reconstruindo o texto em versos na tentativa de provocar a sensação de leitura de uma poesia.

\section{Quadro 3: Segunda Estrofe}

\begin{tabular}{|l|l|}
\hline POESIA EM LIBRAS & TRADUÇÃO PARA O PORTUGUÊS \\
\hline De 08 a 18 segundos do vídeo & Segunda Estrofe \\
\hline & Os olhares silenciosos mudam a rotina \\
& O fogo incendeia, \\
& Desespero que nos consome vivas \\
& 125 vozes foram perdidas \\
\hline
\end{tabular}

Fonte: Elaborado pelas autoras (2020).

A primeira frase da estrofe traduzida foi criada porque na sinalização da autora todas as mulheres param de trabalhar e se olham e um silêncio predomina no ambiente. Em seguida, a autora mostra o local de um incêndio e a aflição das mulheres prevendo que morreriam queimadas. A autora finaliza a estrofe com os números "1-2-5" soletrados. Para a construção da tradução dessa estrofe, pesquisou-se os fatos históricos como o incêndio em uma fábrica têxtil de Nova York em 1911, quando cerca de 125 operárias morreram carbonizadas. A documentação se deu em sites educativos, jornais com matérias sobre o dia das mulheres e blogs feministas. A linguagem assumida na tradução, novamente, pretendeu narrar essa história em estrofes, que além da mensagem provocam uma sonoridade melodiosa e esteticamente harmoniosa procurando usar um léxico diverso e metafórico, como em "nos consome vivas" com "125 vozes foram perdidas". 
"International women day" de Angela Eiko Okumura: tradução comentada de uma poesia... Neiva de Aquino Albres • Larissa Fernandes Dias

\section{Quadro 4: Terceira Estrofe}

\begin{tabular}{|l|l|}
\hline POESIA EM LIBRAS & TRADUÇÃO PARA O PORTUGUÊS \\
\hline De 18 a 36 segundos do vídeo & Terceira Estrofe \\
\hline & $\begin{array}{l}\text { Guerras tomam o controle } \\
\text { Explosões destroem nações } \\
\text { E nós continuamos trabalhando } \\
\end{array}$ \\
\hline
\end{tabular}

Fonte: Elaborado pelas autoras (2020).

Na poesia, a autora explora essa parte com metáforas, ela não explicita o sinal lexical guerra, mas ecoa o som dos tiros, das bombas e explosões ao mesmo tempo que as mulheres permanecem em suas ações manuais fabris e batem seus cartões de trabalho. Na tradução, optou-se por utilizar as palavras "guerra" e "trabalho" não investindo em toda a descrição detalhada tão essencialmente da Libras ou de explicação do funcionamento da língua de partida, mas investindo na sonoridade das estrofes. Essa foi uma escolha consciente nessa tradução considerando que as modalidades das línguas trabalhadas são distintas, causando o que se tem chamado de efeitos de modalidade no processo de tradução. Para Rodrigues (2013, p. 96), "os sinais ao serem enriquecidos com informações gramaticais ou incorporarem as qualidades de um referente, especificando movimento ou posição de pessoas e objetos ou, até mesmo, descrevendo tamanho e forma, demandam um tempo maior dos intérpretes" para sua interpretação em português oral. No caso em destaque, na tradução compreende-se a especificidade da modalidade da língua de partida. Contudo, se atenta além da estrutura linguística ao gênero discursivo poesia que requer outra construção sintática e valoriza-se os possíveis efeitos na língua de chegada (português), empregando em um contínuo, por exemplo, as palavras "explosões", "nações" e "obrigações". 
"International women day" de Angela Eiko Okumura: tradução comentada de uma poesia... Neiva de Aquino Albres • Larissa Fernandes Dias

\section{Quadro 5: Quarta Estrofe}

\begin{tabular}{|l|l|}
\hline POESIA EM LIBRAS & TRADUÇÃO PARA O PORTUGUÊS \\
\hline Do segundo 36 até o 44 & Quarta Estrofe \\
\hline & $\begin{array}{l}\text { Uma se levanta, instigando todas } \\
\text { De repente, somos nós que marchamos } \\
\text { A luta está em nossas mãos } \\
\text { Movimentando o mundo em ação }\end{array}$ \\
\hline
\end{tabular}

Fonte: Elaborado pelas autoras (2020).

No momento em que a autora sinaliza "MANIFESTAÇÃO", ficou perceptível que se inicia as lutas e manifestações das mulheres pelo mundo. Seguidamente, quando representa pessoas marchando, identificou na tradução que todas as mulheres estão juntas para conquistar seus direitos.

Em seguida, a autora anuncia o dia 8 de março como o marco do reconhecimento dessa luta. Na edição do vídeo há uma alteração de cor, já que desde o início da poesia a cor é 'preto e branco' e a partir de agora o colorido é aplicado ao projeto, predominando o verde como cor de fundo e o azul na camiseta da poetisa. Nesse sentido, há uma alteração de cores do vídeo que contribui para a construção de sentidos, passando de um fato triste para um momento de vida, de esperança. Isso é possível pelo recurso tecnológico empregado ajustando contraste, saturação e outros parâmetros do vídeo. Quando traduzimos esse vídeo em Libras para o português escrito, empregamos uma cor diferente à letra, passando do cinza para o verde. 
"International women day" de Angela Eiko Okumura: tradução comentada de uma poesia... Neiva de Aquino Albres • Larissa Fernandes Dias

\title{
Quadro 6: Quinta Estrofe
}

\begin{tabular}{|l|l|}
\hline POESIA EM LIBRAS & TRADUÇÃO PARA O PORTUGUÊS \\
\hline Do segundo 44 até o 57 & Quinta Estrofe \\
\hline & $\begin{array}{l}\text { 8 de março de 1975, } \\
\text { Ganhamos nosso dia. } \\
8 \text { de março de 2019, } \\
\text { Marchamos pela liberdade que nos move }\end{array}$ \\
\hline
\end{tabular}

Fonte: Elaborado pelas autoras (2020)

Quando a autora expressa o sinal em Libras identificado por "ASSINAR" associada à legenda que apresenta o ano de 1975, data que foi declarado o dia da mulher, novamente foi requerido das tradutoras a pesquisa pelo marco histórico e seu fundamento. A opção das tradutoras foi apresentar na tradução o ano, mostrando o reconhecimento dessa data. Conforme o andamento do vídeo, percebe-se que as mulheres estão felizes pela conquista do dia, mas, nos dias atuais, percebem que precisam manter a luta, portanto, na tradução manteve-se o objetivo em que as mulheres estão em direção a outras conquistas, como o respeito, igualdade de direitos, liberdade de expressão.

\begin{abstract}
O 8 de março deve ser visto como momento de mobilização para a conquista de direitos e para discutir as discriminações e violências morais, físicas e sexuais ainda sofridas pelas mulheres, impedindo que retrocessos ameacem o que já foi alcançado em diversos países. (SELIM, 2018, s.p.).
\end{abstract}

Assim, a autora da poesia finaliza sua obra. Mesmo uma obra poética, subjetiva e feminista carrega a vivência do seu autor e das múltiplas vozes. Uma história de outras mulheres é contada incluindo e identificando a autora como parte desse movimento; o que é social reaparece como de si próprio, do que a autora surda expressa por meio de sua língua, para uma minoria linguística e duplamente discriminada. 
"International women day" de Angela Eiko Okumura: tradução comentada de uma poesia... Neiva de Aquino Albres • Larissa Fernandes Dias

Essa poesia em português é um novo projeto discursivo, inteiramente único, concomitantemente de cunho social, recriada pelas tradutoras também mulheres, descortina um real indissolúvel, cravado em palavras do português que pretende reverberar uma produção em língua de sinais. Porque, “[...] o poeta [...] não escolhe suas palavras de um dicionário, mas do contexto da vida no qual as palavras se sedimentam e se impregnam de valorações [...]" (VOLOCHÍNOV, 2013, p. 88). Então, reside nesse movimento tradutório a capacidade do artista, de aprofundamento no exterior, por meio da exotopia e, após isso, o retorno a si mesmo, com atitude contemplativa.

O olhar exotópico compõe o atributo humano de significar. A destreza de se considerar o outro que lhe perpassa e, por vezes, apropriar-se de seus elementos constitutivos é um fenômeno presente em todos os terrenos da vida. A cientificidade, a história, a vida cotidiana são estâncias dum sempre compartilhar. O ser age, essencialmente, pelo outro e para outro. E não é diferente no processo artístico, pois o artista recupera um pouco de si e de todos, por isso a arte possui um reconhecido caráter universal. Desta maneira, arte e vida são indissociáveis, estabelecendo relações diretas, equivalentes à medida que o real é reinventado e, portanto, refletido e refratado. (AMORIM; SOUSA, 2013, p. 1184).

O que decorre, então, dessa perspectiva é a concepção do autor da poesia como sujeito histórico e social assim como o tradutor, pois, de acordo com a filosofia bakhtiniana, a linguagem se configura no e pelo outro, o que se contrapõe às ideias de essencialismo linguístico, que enfatiza a dimensão instrumental da linguagem e despersonifica a língua. O essencialismo compreende a língua como uma expressão inata, pura e neutra.

A competência discursiva do tradutor se fez essencial para a construção dessa tradução. O foco esteve no gênero poesia, e as autoras apresentaram os traços das decisões tomadas no proces- 
"International women day" de Angela Eiko Okumura: tradução comentada de uma poesia... Neiva de Aquino Albres • Larissa Fernandes Dias

so de tradução como algo individual em função da sua situação de escrita particular.

Nesse sentido, toda e qualquer manifestação humana possui significado porque nasce do encontro entre o "eu" e o "outro", corroborando a concepção de que a poesia como uma literatura surda produzida por uma mulher surda e traduzida por mulheres ouvintes para outro grupo é um produto social e polifônico. A tradução é essencialmente polifônica, pois "o caráter específico que confere valor artístico à palavra literária é sua objetificação, sua representação, expressa na posição do outro, e não do eu" (PONZIO, 2012, p. 208). Afirmamos que tanto a poesia em Libras quanto a tradução para o português são autorias e atos de experiência com a linguagem.

Finalizamos a seção de análise com a poesia de Angela Eiko Okumura, traduzida:

\title{
DIA INTERNACIONAL DAS MULHERES
}

\author{
Em épocas remotas \\ Nossa felicidade era inexistente \\ Representadas como máquinas de produção \\ Vivendo sem um sorriso aparente
}

Os olhares silenciosos mudam a rotina

O fogo incendeia

Desespero que nos consome vivas

125 vozes foram perdidas

Guerras tomam o controle

Explosões destroem nações

E nós continuamos trabalhando

Porém, fartas dessas obrigações

Uma se levanta, instigando todas

De repente, somos nós que marchamos 
"International women day" de Angela Eiko Okumura: tradução comentada de uma poesia... Neiva de Aquino Albres • Larissa Fernandes Dias

\author{
A luta está em nossas mãos \\ Movimentando o mundo em ação
}

8 de março de 1975

Ganhamos nosso dia

8 de março de 2019

Marchamos pela liberdade que nos move

Tradução: Larissa Fernandes Dias e Neiva de Aquino Albres

\title{
Considerações finais
}

Com os comentários provenientes dessa tradução, por meio da análise do processo e reflexões das tradutoras, conforme indicado na introdução deste texto, espera-se contribuir tanto com o campo dos Estudos da Tradução e Interpretação de Línguas de Sinais (ETILS) quanto, e principalmente, para o ensino de tradução.

Comecemos pela formação, é de extrema importância ressaltar que a tarefa de traduzir um texto de partida de gênero poético para um texto de chegada de mesmo gênero, mas de línguas de modalidades diferentes, como também a diferença de suporte para a linguagem, do vídeo para a escrita, exige diversas competências do tradutor. Damos destaque às competências discursivas, de conhecimento dos gêneros discursivos e das multimodalidades, como o conhecimento de estratégia tradutórias.

A própria tradução comentada como atividade pedagógica propicia a reflexão e a discussão com o professor orientador, o que refina o olhar para o fazer tradutório. O processo se dá desde a leitura do texto de partida até modos de pesquisar outros materiais já realizados, além disso, com apoio profissional durante $o$ processo e pela negociação de sentidos. Assim, a dinâmica pedagógica assumida em disciplina no curso Letras-Libras de tradução 
"International women day" de Angela Eiko Okumura: tradução comentada de uma poesia... Neiva de Aquino Albres • Larissa Fernandes Dias

comentada como uma construção conjunta entre dois tradutores (professor e aluno) e por estudar os processos do projeto de tradução para construção dos efeitos de sentido respeitando o gênero discursivo contribuiu para a efetivação do projeto de tradução, bem como à aprendizagem de ambas as tradutoras.

Outro ponto de igual importância está na sensibilidade e na atividade criativa e estética do tradutor, na afinidade com o gênero poesia e na sensibilidade para leitura em plataformas digitais a fim de produzir a tradução de uma poesia. Da mesma forma que a familiaridade com as obras de literatura surda produzidas a partir de suportes digitais, em contexto heterogêneo promovido pelas tecnologias audiovisuais, se faz fundamental e trabalhado na referida formação (curso para tradutores) pela apreciação de diversas obras de diferentes gêneros discursivos produzidos por autores surdos.

Sobre a tradução, foi possível apreender que essa poesia em Libras possui diversas características, gestos, ações, descrições, posições corporais e expressões faciais que completam a expressão poética, como também a repetição de sinais estruturados de acordo com o sentido desse gênero literário. Para identificar alguns aspectos na versão em português, a estratégia utilizada foi separar por estrofes e a construção de rimas para enfatizar o sentido da poesia.

Conclui-se que a poesia é um gênero possível de ser traduzido desde que o tradutor seja livre para sentir, criar e se aventurar na literatura como um autor da tradução.

\section{Referências}

AMORIM, Marília; SOUSA, D. O eu-outro. In: GALVÃO, V. et al. (orgs.).

Anais do Simpósio Mundial de Estudos de Língua Portuguesa. UFG, Goiânia: FUNAPE, 2013, p. 1182-1887. 
"International women day" de Angela Eiko Okumura: tradução comentada de uma poesia... Neiva de Aquino Albres • Larissa Fernandes Dias

BASSNETT, Susan. Translation studies, 3 ed. London/New York: Routledge. 2003.

BRAIT, Beth. Análise e Teoria do Discurso. In: BRAIT, B. (org.). Bakhtin: Outros Conceitoschave. São Paulo: Contexto, 2006. p. 9-31.

CAMPOS, Haroldo. A operação do texto. São Paulo: Perspectiva, 1976. p. 9-13.

CAMPOS, Haroldo de. Da tradução como criação e como crítica. In: CAMPOS, Haroldo de. Metalinguagem \& Outras Metas. São Paulo: Perspectiva, 1992. p. 31-48.

CAS-MS. Lei Maria da Penha. A Subsecretaria de Políticas Públicas para Mulheres (SPPM) - ligada à Secretaria de Estado de Direitos Humanos Assistência Social e Trabalho (Sedhast). Tradução para Libras: Cláudio Luiz Vasques dos Santos; Gislaine da Luz Nunes; Larissa Sisti Lima; Tamires Bessa da Silva. Campo Grande - MS, 2016.

DE PAULA, Luciane. Círculo de Bakhtin: uma Análise Dialógica de Discurso. Revista de estudos da linguagem, [S.I.], v. 21, n. 1, p. 239258, june 2013. Disponível em: http://www.periodicos.letras.ufmg.br/ index.php/relin/article/view/5099. Acesso em: 18 jul. 2020.

KARNOPP, Lodenir. Literatura Surda. Universidade Federal de Santa Catarina Licenciatura em Letras-Libras na Modalidade a Distância. Florianópolis, 2008. Disponível em: http://www.libras.ufsc.br/colecaoLetrasLibras/eixoFormacaoEspecifica/literaturaVisual/assets/369/ Literatura_Surda_Texto-Base.pdf. Acesso em: 1 abr. 2020.

KARNOPP, Lodenir; MACHADO, Rodrigo N. Literatura Surda: ver histórias em línguas de sinais. In: SEMINÁRIO BRASILEIRO DE ESTUDOS CULTURAIS EM EDUCAÇÃO - SBECE, 2., 2006. Anais [...]. Canoas: ULBRA, 2006. p. 1-14. CD-ROM.

LARANJEIRA, Mário. Poética da tradução: do sentido à significância. São Paulo: Editora da Universidade de São Paulo, 1993. MCCLEARY, Leland; VIOTTI, Evani. C.; LEITE, Tarcísio. Descrição de línguas sinalizadas: a questão da transcrição dos dados. Alfa, São José do Rio Preto, v. 54, n.1, p. 265-289, 2010. Disponível em: https://periodicos. fclar.unesp.br/alfa/article/view/2880/2654. Acesso em: 21 jul. 2019. 
"International women day" de Angela Eiko Okumura: tradução comentada de uma poesia... Neiva de Aquino Albres • Larissa Fernandes Dias

PAES, José Paulo. Tradução: a ponte necessária. Aspectos e problemas da arte de traduzir. São Paulo: Ática, 1990.

OKUMURA, Angela Eiko. 4sentidosmidia, instagram. Florianópolis, 08 de março de 2019. Disponível em: https://www.instagram.com/p/ BuvY17NIDdC/. Acesso em: 10 de junho de 2020.

SELEM, Maria Célia Orlato. Por que 8 de março é o Dia Internacional da Mulher? [Entrevista cedida a] Paula Nadal. Nova Escola, São Paulo, 7 mar. 2018. Disponível em: https://novaescola.org.br/conteudo/301/ por-que-8-de-marco-e-o-dia-internacional-da-mulher. Acesso em: 1 abr. 2020.

PERLIN, Glades; VILHALVA, Shirley. Mulher Surda: elementos ao empoderamento na política afirmativa. Revista Fórum, Rio de Janeiro, v. 0, n. 33, p. 1-12, 2016. Disponível em: https://www.sumarios.org/artigo/ mulher-surda-elementos-ao-empoderamento-na-pol\%C3\%ADtica-afirmativa. Acesso em: 1 abr. 2020.

PONZIO, A. A revolução bakhtiniana: o pensamento de Bakhtin e a ideologia contemporânea/Augusto Ponzio. Coordenação de tradução: Valdemir Miotello. 2. ed. São Paulo: Contexto, 2012.

PYM, Anthony et al. Exploring Translations Theories. Cadernos de Tradução, Florianópolis, v. 36, n. 3, p. 214-317, set. 2016. ISSN 21757968. Disponível em: https://periodicos.ufsc.br/index.php/traducao/ article/view/2175-7968.2016v36n3p214. Acesso em: 1 abr. 2020.

RODRIGUES, Carlos Henrique. A interpretação para a língua de sinais brasileira: efeitos de modalidade e processos inferenciais. $254 \mathrm{f}$. Tese (Doutorado em Letras) - Faculdade de Letras, Universidade Federal de Minas Gerais, Belo Horizonte, 2013. Disponível em:

https://repositorio.ufmg.br/bitstream/1843/MGSS-9CXQ8L/1/rodrigues_2013_tese_poslin.pdf. Acesso em: 1 abr. 2020.

ROHLING, Nívea. A pesquisa qualitativa e análise dialógica do discurso: caminhos possíveis. Cadernos de Linguagem e Sociedade, Brasília, v. 15, n. 2, p. 44-60, 2014. Disponível em: https://periodicos.unb.br/index. php/les/article/view/7561. Acesso em: 10 jun. 2020. 
"International women day" de Angela Eiko Okumura: tradução comentada de uma poesia... Neiva de Aquino Albres • Larissa Fernandes Dias

SANTOS, Silvana Aguiar dos Santos; STUMPF, Marianne Rossi. Cartilha sobre violência doméstica - perguntas e respostas: experiências de tradução do português para Libras. In: Revista Espaço, Rio de Janeiro, v. ?, n. 51, p. 39-58, jan-jun, 2019. Disponível em: http://www.ines.gov. br/seer/index.php/revista-espaco/article/view/598/659. Acesso em: 18 mar. 2021.

SOBRAL, Adail. Posfácio. In: BENEDETTI, Ivone; SOBRAL, Adail (org). Conversas com tradutores: balanços e perspectivas da tradução. São Paulo: Parábola. 2003, p. 201-214.

SOBRAL, Adail Ubirajara. Dizer o mesmo aos outros: ensaios sobre tradução. São Paulo: Special Book. Service Livraria, 2008.

SUTTON-SPENCE, Raquel et al. Os craques da Libras: a importância de um festival de folclore sinalizado. Revista Sinalizar, Goiânia, v. 1, p. 78-92, 2016. Disponível em: https://revistas.ufg.br/revsinal/article/ view/35847/20227 Acesso em: 18 mar 2021.

VOLOCHÍNOV, Valentin Nikolaevich. A construção da enunciação e outros ensaios. São Carlos: Pedro \& João Editores, 2013. 